УДК 372.881.161.1

\title{
РУССКИЕ ПОТАМОНИМЫ КАК ЭЛЕМЕНТЫ ПРИРОДНО-ЛАНДШАФТНОГО КОДА РУССКОЙ КУЛЬТУРЫ (ОПЫТ ИДЕОГРАФИЧЕСКОГО ОПИСАНИЯ)
}

\author{
Чжан Сюэай \\ аспирант \\ Гуманитарный институт \\ Санкт-Петербургский политехнический университет \\ Петра Великого (СПбПУ)
}

\begin{abstract}
Аннотация: В статье рассматриваются русские названия рек как важнейшие элементы природно-ландшафтного кода. Автор кратко характеризует актуальность подобного исследования, указывая, что знание о восприятии русским человеком природы и окружающего мира составляет важнейшую особенность национальной языковой картины мира. Освоение культуры и ментальности русского народа является главной задачей в процессе формирования лингвокультурной компетенции изучающих русский язык как иностранный. Автор статьи полагает, что русские потамонимы обладают в этом плане большим потенциалом.
\end{abstract}

Ключевые слова: Природно-ландшафтный код культуры, русский язык как иностранный, потамонимы.

\section{RUSSIAN POTAMONYMS AS ELEMENTS OF THE NATURAL LANDSCAPE CODE OF RUSSIAN CULTURE (THE EXPERIENCE OF IDEOGRAPHICAL DESCRIPTION)}

\section{Zhang Xueai}

\begin{abstract}
The article considers the Russian river names as the capital elements of the natural landscape code. The author briefly characterizes the relevance of the research, pointing out that knowledge about the perception of nature and the surrounding world by Russians is the main feature of the national linguistic picture of the world. Mastering the culture and mentality of the Russian people is the main task in the process of forming the linguocultural competence of students of Russian as a
\end{abstract}


foreign language. The author of the article believes that Russian potamonyms have great potential in this regard.

Key words: Natural-landscape code of culture, russian as a foreign language, potamonyms.

Формирование вторичной языковой личности в методике преподавания русского языка как иностранного ориентируется на освоение иностранными учащимися культуры и ментальности носителей русского языка. При этом обязательным условием успешного вхождения в «чужую» культуру становится усвоение базовых лингвистических знаний, к которым относятся, по мнению О.И. Халупо, «основные компоненты системы языка (ключевые слова, словосочетания, фразеологические единицы и прецедентные тексты), отражающие национально-культурную специфику общества, детерминированные системой ценностей общества и позволяющие личности обеспечить развитие способностей, формирование мировоззрения и духовности, достойную подготовку ее к жизнедеятельности в обществе» [1, c. 126]. Такие лингвистические знания составляют содержание лингвокультурной компетенции, которая предполагает осознание инофоном изучаемого языка как формы выражения национальной культуры, тесно связанной с историей данного народа, а также овладение его духовными и ментальными ценностями.

Указанные процессы не могут осуществиться без освоения иностранным учащимся значительного фрагмента национальной картины мира, которую формирует отношение русского человека к естественной природе, а также языковой картины мира, которую составляют имена естественных географических объектов (гор, рек, лесов, озер и т.д.) или их элементов, включая элементы ландшафта, освоенного человеком (например, прудов, водохранилищ, дорог и под.). Данная совокупность имен составляет природноландшафтный культурный код [2], который тесно взаимодействует с другими культурными кодами, список которых на данный момент остается открытым. Так, Лян Сяонань, сравнивая культурные коды, характерные для русского и китайского языкового сознания, выделил их одиннадцать: «космогонический, растительный, зооморфный, природно-ландшафтный, антропный, предметный / вещный, архитектурный, соматический, пищевой, аксиональный, духовный» [3, с. 52]. Ли Юецзяо, Г.М. Васильева считают, что их количество приближается к сорока [4]. В любом случае, однако, природно-ландшафтный 
код культуры выделяется и исследуется многими учеными на материале различных языков [5], [6], [7].

Цель настоящей статьи - описать особенности представления русским человеком такого водного естественно-природного объекта, как река, через идеографический анализ способов номинации рек и фиксации результатов этой номинации в русском ономастиконе, а также выявить лингвометодический потенциал данного описания для методики преподавания русского языка как иностранного.

Россия - страна, обладающая огромным количеством рек и озер. Сколько их точно в России, не представляется возможным посчитать. Реки издавна не только являлись источником жизнедеятельности русского народа, но и во многом стали культурными символами России [8], [9]. Именно потому, что вся этническая и культурная история русского народа была тесно связана с его морями, реками и озерами, болотами и прудами в русском ономастическом пространстве выделяется такой внушительный пласт гидронимов, а среди них потамонимов (имена собственные рек). Для инофона чрезвычайно полезно ознакомиться со структурно-семантическими типами потамонимов, во-первых, потому, что они явно демонстрируют архаичные и современные (продуктивные и непродуктивные) модели словообразования в русском языке; во-вторых, наблюдая процесс «объект номинации - результат номинации», запечатленный в названиях рек, можно увидеть предпочтительные способы переноса лексического значения, которые русский народ использует для именования рек в своем природно-ландшафтном культурном коде; в-третьих, анализируя список потамонимов, можно выявить особенности русской языковой картины мира, которые отражаются только в этом архаичном лексическом пласте.

Список потамонимов, собранный автором, представлен 320 наименованиями. Данные потамонимы собирались по словникам других исследователей, а также по материалам разных топонимических словарей. Отдельную процедуру работы составил сбор потамонимов через сервисы карт Google и Яндекс. На данный момент последний способ является наиболее точным и мобильным.

Идеографическое распределение потамонимов проводилось по номинативным признакам, отражающим: 1) прямые качества и свойства объекта; 2) опосредованные качества и свойства объекта, проявляющиеся через его связи с другими объектами; 3) опосредованные качества и свойства объекта, проявляющиеся через его связи с субъектом. Эти три большие группы 
неоднородны по своему составу, поэтому в зависимости от конкретного семантического признака внутри них выделяются более мелкие группы. Ниже анализу подвергаются только те потамонимы, внутренняя форма которых легко определяется. Архаичные названия со стертой внутренней формой исклчены из данной классификации.

Итак, проведенный анализ позволил выявить следующие потамонимы.

\section{І. Потамонимы, называющие прямые свойства и качества объекта.}

1.1. Характер течения (однословные: p. Быстрая, р. Громотуха, p. Быстрица, p. Быстрянка, p. Бурная, p. Бурный, р. Бурновка, p. Бурня, p. Бешеная, p. Бешенка, p. Медленная, p. Медлянка, p. Медленный, p. Кипучая, p. Кипучий; словосочетания: р. Быстрый Проток, р. Быстрый Исток, р. Быстрый Ключ, р. Бурный Ключ, и др.).

1.2. Температура воды (однословные: р. Горячая, р. Талая, р. Теплая, p. Жара, р. Жаркова, р. Жарча, р. Холодная, р. Мерзлая, р. Снежная, р. Ледянка; словосочетания: p. Горячий Ключ, р. Горячие Ключи, р. Ледяная Рассоха, p. Холодные Ключи, и др.).

1.3. Глубина (однословные: p. Глубокая, р. Дно, р. Бездна, р. Бездонка, p. Полная, р. Полноводная, р. Полна, р. Мелкая, р. Неглубка, р. Аршин, p. Вершок; словосочетания: p. Бездонный Ключ, р. Мелкий Ключ и др.).

\section{4. Размер}

1.4.1. Длина (однословные: р. Длинная, р. Долгая, р. Долгуша, р. Долгота, p. Долговка, p. Бесконечная, p. Верста; словосочетания: p. Длинный Ключ, p. Длинный Увыл, р. Длинный Увал, р. Долгие Терси, р. Малый Волховец, и др.).

1.4.2. Ширина (однословные: р. Большая, р. Широкая, р. Великая, p. Величка, p. Средняя, p. Маленькая, p. Ручей; словосочетания: p. Широкая Падь, р. Большая Нева, р. Маленькая речка и др.).

1.4.2. Объем (однословные: р. Плоская, р. Гладкая, р. Плоскодырь, р. Гладыш; словосочетания: р. Гладкий Ключ, р. Горячие Ключи, р. Ледяная Рассоха, р. Холодные Ключи, и др.).

1.5. Чистота, цвет и прозрачность (однословные: p. Чистая, p. Чистенькая, р. Белая, р. Светлая, р. Прозрачная, р. Голубая, р. Вязкая, p. Топкая, р. Черная, р. Ржавая (по бурому цвету воды), р. Свинцовая, р. Рудная, р. Желтая, р. Серебряная, р. Зеркальная, р. Поганец, р. Мутная; словосочетания: р. Светлый Ключ, и др.). 
1.6. Форма (однословные: p. Прямая, р. Извилинка, р. Извилистая, p. Вилюй, p. Кривун, p. Кривуша, р. Кольцовка, р. Угловая, р. Угловка; словосочетания: p. Кривые Колена, р. Прямые Ключи, и др.).

1.7. Вкус воды (однословные: p. Соленая, p. Пресная, р. Кислая, р. Горькая; словосочетания: р. Горькая Речка, р. Кислый Ключ, р. Кислая Оять, и др.).

1.8. Запах (однословные: p. Вонючка, p. Вонька, и др.).

1.9. Водный режим (однословные: р. Падун, р. Разлив, р. Сухая, p. Пересыхающая; словосочетания: p. Сухой Ручей, и др.).

II. Потамонимы, отражающие опосредованные качества и свойства объекта, проявляющиеся через его связи с другими объектами.

2.1. Положение в пространстве (однословные: р. Дальняя, р. Далекая, p. Близкая, p. Наша, р. Своя; словосочетания: р. Дальняя Керша, р. Глухая Падь, и др.).

2.2. Положение к югу, северу, западу и востоку (однословные: р. Южная, p. Северная, p. Восточная; словосочетания: p. Западная Двина, p. Восточная Лица Падь, и др.).

2.3. Порядок по счету или количество (однословные: р. Первушка, p. Пятериха; словосочетания: p. Первая Речка, р. Четвертый километр, р. Семь Грехов, и др.).

2.4. Положение по отношению $\kappa$ другим объектам (однословные: p. Внутренняя, p. Боковушка, p. Передняя, p. Задняя; словосочетания: p. Задний Алтан, р. Передняя Элиста, и др.).

III. Потамонимы, отражающие опосредованные качества и свойства объекта, проявляющиеся через его связи с субъектом

\section{1. Человек}

3.1.1. Части тела человека (однословные: p. Нос, р. Глазкина, р. Губа, p. Уши, p. Рука, p. Головка, p. Головань; словосочетания: p. Нижняя Нога, p. Чертов Нос, Малая Крутая Губа и др.).

3.1.2. Имена (однословные: р. Аннушка, р. Ивановка, р. Марьина, p. Ольгинская, р. Борисовка, и др.).

3.1.3. Одежда человека (однословные: р. Штаны, р. Рукав, р. Сапоговка, p. Рубашка, p. Тулупиха; словосочетания: р. Малая Кафтанчикова, и др.).

3.1.4. Религиозные верования (однословные: р. Святая, р. Монастырка, p. Часовенский, р. Воздвиженка, и др.). 
3.1.5. Языческие представления (однословные: р. Волхов, р. Ведьма, p. Идол, р. Скоморошка; словосочетания: р. Леший Ключ, и др.).

3.1.6. Вид деятельности человека и связанные с ней хозяйственные постройки (однословные: p. Кузнецовка, p. Амбар, p. Мельничная, р. Пастушка, р. Рига, р. Винокурка, и др.).

3.2. Флора (однословные: р. Лесная, р. Луга, р. Цветочная, р. Ромашка, p. Василек, р. Березовка, р. Кедровая; словосочетания: р. Еловая Рассоха, р. Дубовый Ровец, и др.).

3.3. Фауна (однословные: p. Лебяжья, p. Лебяжка, p. Медведица, p. Волчья, p. Белка, p. Коровка, p. Лисичка, p. Конья; словосочетания: p. Медвежий Ключик, р. Олений глаз, р. Заячий Ключ, и др.).

Безусловно, данная классификация требует уточнения, и прежде всего по региональному аспекту. Кроме того, огромный интерес представляет выяснение специфика «переключения», или «наслоения», культурных кодов в названиях рек. Например, природно-ландшафтного и соматического (см. п. 3.1.1), природно-ландшафтного и зооморфного (см. п.п. 3.2, 3.3), природноландшафтного и артефактного (см. п.п. 3.1.3, 3.1.6) и т.д. Данные вопросы относятся $\mathrm{\kappa}$ перспективам исследования лингвокультурного потенциала русских потамонимов. Тем не менее, уже на этом этапе изучения мы можем сделать вывод о высокой степени идиоэтничности русских названий рек, которая проявляется в детальном отображении окружающей природы и самого человека, как и результатов его деятельности. Несомненно, углубление подобных сведений в практике преподавания русского языка как иностранного окажутся чрезвычайно полезными для выяснения особенностей национальной языковой картины русского человека и его лингвокультуры

\section{Список литературы}

1. Халупо О.И. Базовые единицы лингвокультурной компетенции носителя языка // Язык и культура. 2012. №2 (18). С. 123-131.

2. Телия В. Н. О феномене воспроизводимости языковых выражений // Язык, сознание, коммуникация. М.: МАКС Пресс, 2005. С. 4-42.

3. Лян Сяонань. Русский темпоральный код в свете лингвокультурологического подхода (на фоне китайского языка): дис. ... канд. филол. наук. M., 2008. - 175 c. 
4. Ли Юецзяо, Васильева Г.М. Растительный код культуры в лексике языка (фитонимы): учебный словарь. - Вып. 1. Вербальные кодыкультуры в лексике языка. - СПб.: Изд-воРГПУ им. А.И. Герцена, 2020. - 66 с.

5. Кольовска Е.Г. Природно-ландшафтный код в аспекте лингводидактики: дис. ... канд. филол. наук. - М., 2014. - 240 с.

6. Сарач X. Природно-ландшафтный код культуры на материале русского и турецкого языков: дис. ... канд. филол. наук. - М., 2016. - 221 с.

7. Шустова С.В., Носкова И.В. Природно-ландшафтный код в английской культуре // ART LOGOS. 2019. №1 (6). С. 111-119.

8. Семенова Н.В. Реки в русском культурном пространстве // На пересечении языков и культур. Актуальные вопросы гуманитарного знания: Русский язык и русская литература в поликультурном пространстве XXI века: материалы I Международной научно-практической конференции (27-29 апреля 2016 г., г. Киров, Россия), «Университет-Плюс», 2016 г. №. 2-3 (8) Стр. 61-65.

9. Семенова Н.В. Русский язык как иностранный. Русские культурные реалии : учеб. пособие / Н. В. Семёнова, А. В. Рубцова. - СПб. : ПОЛИТЕХПРЕСС, 2021. - $138 \mathrm{c}$. 